\title{
Mid-term results of mitral valve repair using flexible bands versus complete rings in patients with degenerative mitral valve disease: a prospective, randomized study
}

\author{
Alexandr V. Bogachev-Prokophiev, Alexandr V. Afanasyev*, Sergei I. Zheleznev, Vladimir M. Nazarov,
} Ravil M. Sharifulin and Alexandr M. Karaskov

\begin{abstract}
Background: We aimed to compare the outcomes of mitral valve repair with flexible band (FB) versus complete semirigid ring (SR) in degenerative mitral valve disease patients.

Methods: From September 2011 to 2014, 171 patients were randomized and underwent successful mitral valve repair using a SR $(n=85)$ or FB $(n=86)$. There were no significant between-group differences at baseline.

Results: There were no early mortalities. The mean follow up was 24.7 months. The 2-year survival was $96.0 \pm 2.3 \%$ (95\% confidence interval [Cl], 88.6-98.7\%) and $94.3 \pm 2.8 \%(95 \% \mathrm{Cl}, 85.5-97.9 \%)$ in the SR and FB groups, respectively ( $p=0.899)$. The left ventricle remodeling was similar between the groups. Higher transmitral peak $(8.5$ [3.9-17] vs. 6 [2.1-18] mmHg, $p<0.001)$, mean pressure gradients (3.7 [1.3-8] vs. 2.8 [0.6-6.8] mmHg, $p=0.001)$, and systolic pulmonary artery pressure (34.5 [20-68] vs. 29.5 [8-48] mmHg, $p<0.001$ ) was observed in the SR group. The 2-year freedom from recurrence of significant mitral regurgitation was significantly higher in the FB group than the SR group $(p=0.002)$. Residual mitral regurgitation was an independent prognostic factor of recurrence of mitral regurgitation. The 3-year freedom from reoperation was significantly higher in the FB group than the SR group $(p=0.044)$.
\end{abstract}

Conclusion: Patients with degenerative mitral valve disease may benefit from valve repair with FBs. Residual mitral regurgitation before discharge is an independent risk factor of late insufficiency recurrence.

Trial registration: ClinicalTrials.gov NCT03278574, retrospectively registered on 06.09.2017.

Keywords: Degenerative mitral valve disease, Mitral regurgitation, Mitral valve repair

\section{Background}

In 1957, Lillehei et al. [1] proposed the mitral annuloplasty technique, a new concept in valve surgery. Remodeling annuloplasty, developed by Carpentier in 1983, increases leaflet coaptation, prevents future annular dilatation, and preserves leaflet mobility in patients with degenerative mitral valve (MV) disease [2,3]. Currently, there are many commercially available mitral annuloplasty devices in the market, including complete or partial, rigid or flexible, and flat or saddle-shaped rings. However, no single annuloplasty

\footnotetext{
* Correspondence: av.afanasyev@icloud.com

Heart Valves Surgery Department, Meshalkin National Medical Research Center Ministry of Health Russian Federation, 15 Rechkunovskaya street, Novosibirsk, Russian Federation630055
}

device has been proven to have a clinical benefit above the others [4]. Theoretically, the flexible band does remodel mitral annulus providing reduction annuloplasty only. However, the rigid ring does not have enough flexibility for physiological annular motion during the cardiac cycle. A systematic review of clinical trials [5] showed comparable clinical outcomes between rigid and flexible rings. Currently, mitral ring selection is based on a surgeon's preference rather than evidence [6]. Semirigid rings combine flexibility and stability; however, their clinical benefit has not been completely clarified. The present study aimed to compare the outcomes of MV repair with a flexible posterior annuloplasty band versus complete semirigid ring in patients with degenerative MV disease. 


\section{Methods}

\section{Study design}

In this prospective, randomized study, 171 patients with degenerative MV disease who were scheduled for isolated MV repair in our Institute from September 2011 through September 2014 were enrolled (CONSORT flow diagram, Figure 1). Participants were randomly assigned following a simple randomization procedure to complete semirigid ring (SR group) or flexible posterior annuloplasty band (FB group), according to computerized random numbers on the day before surgery. Eligible participants were adults aged 18 years or more with degenerative MV disease [7] who met the indications for MV operation according to the American College of Cardiology/American Heart Association guidelines [8]. Exclusion criteria were previous open cardiac surgery, indication for concomitant aortic valve replacement, or left ventricle (LV) impairment (ejection fraction $<40 \%)$. The Local Ethics Committee approved the study design, and all the patients provided informed consent. The present study was conducted in compliance with the Declaration of Helsinki.

\section{Patients}

Mean age of the participants in each group was 57 (23-75) and 54 (19-74) years, respectively. There were no differences in sex, age, preoperative New York Heart Association (NYHA) functional class, and comorbidities (Table 1).

\section{Outcome measures}

The primary endpoint was freedom from moderate or severe mitral regurgitation (MR) recurrence. Secondary endpoints included survival, freedom from reoperations, and freedom from severe MR recurrence. The severity of MR was evaluated and defined in accordance with the recommendations [9]. Valve-related complications were evaluated and defined in accordance with the guidelines [10].

\section{Surgical techniques}

Real-time two-dimensional/three-dimensional transesophageal echocardiography (TEE, Phillips iE33, Philips Ultrasound Inc., PA, USA) was performed after the induction of anesthesia for MV lesion estimation. Cold crystalloid

\section{CONSORT Flow Diagram}

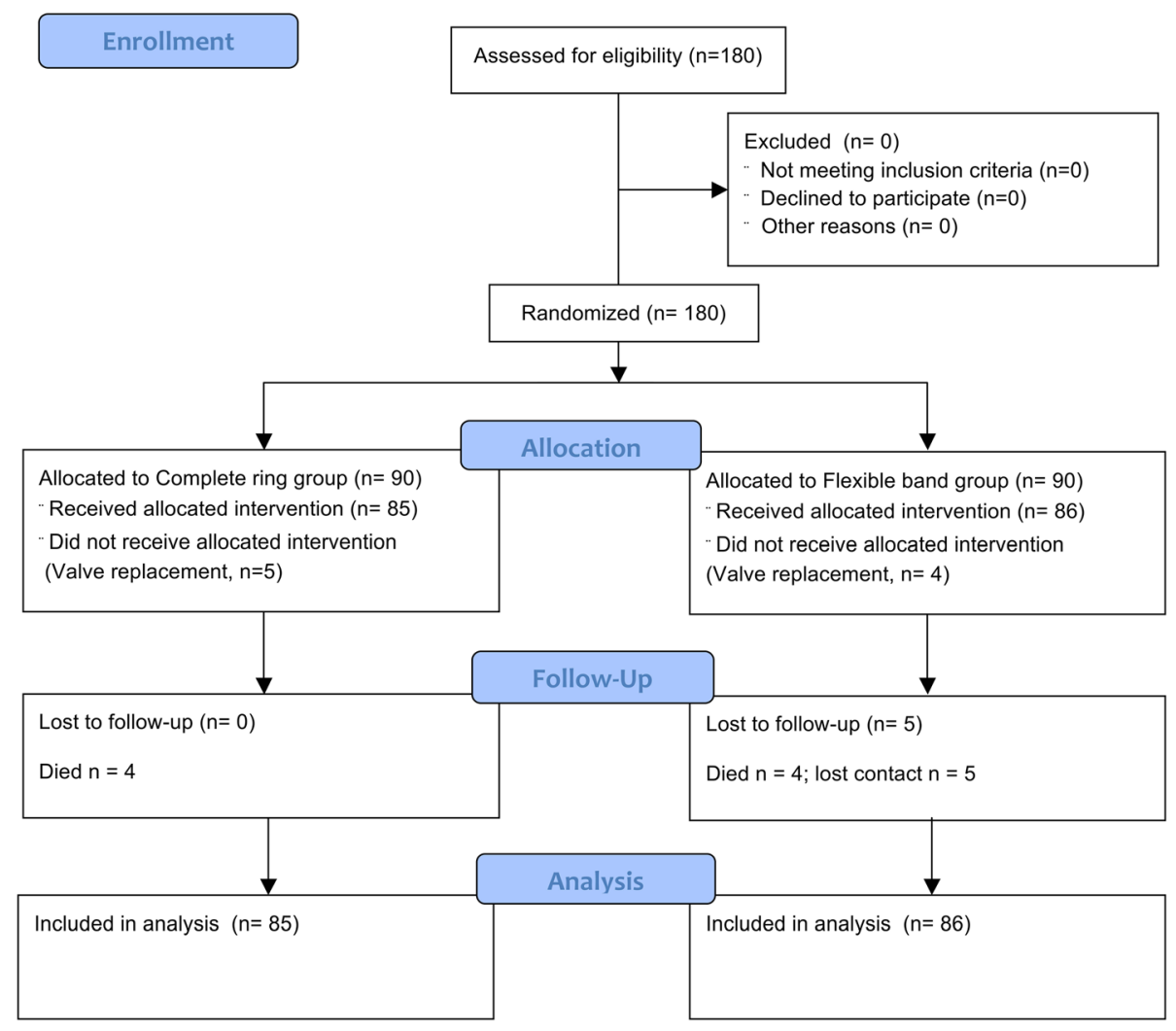

Fig. 1 Consort flow diagram 
Table 1 Baseline

\begin{tabular}{|c|c|c|c|}
\hline & $\begin{array}{l}\text { SR Group, } \\
n=85\end{array}$ & $\begin{array}{l}\text { FB Group, } \\
n=86\end{array}$ & $P$ value \\
\hline FED, n (\%) & $65(76.5)$ & $56(65.1)$ & 0.103 \\
\hline Forme fruste, n (\%) & $12(14.1)$ & $18(20.9)$ & 0.241 \\
\hline Barlow, n (\%) & $8(9.4)$ & $12(14.0)$ & 0.355 \\
\hline Male, n (\%) & $59(69.4)$ & $58(67.4)$ & 0.782 \\
\hline Age, years & $57(23-75)$ & $54(19-74)$ & 0.092 \\
\hline Height, cm & $173(148-192)$ & $175(151 ; 193)$ & 0.079 \\
\hline Weight, kg & $79.1 \pm 14.6$ & $77.1 \pm 16.4$ & 0.388 \\
\hline $\mathrm{BMl}, \mathrm{kg} / \mathrm{m}^{2}$ & $26.9 \pm 4.3$ & $25.4 \pm 4.6$ & 0.522 \\
\hline $\mathrm{BSA}, \mathrm{m}^{2}$ & $1.94 \pm 0.21$ & $1.93 \pm 0.24$ & 0.801 \\
\hline NYHA I, n (\%) & $7(8.2)$ & $12(14.0)$ & 0.234 \\
\hline NYHA II, n (\%) & $22(25.9)$ & $29(33.7)$ & 0.263 \\
\hline NYHA III, n (\%) & $54(63.5)$ & $43(50.0)$ & 0.742 \\
\hline NYHA IV, n (\%) & $2(2.4)$ & $2(2.3)$ & 0.991 \\
\hline$A F, n(\%)$ & $22(25.9)$ & 16 (18.6) & 0.252 \\
\hline Paroxysmal, n (\%) & $2(2.4)$ & $2(2.3)$ & 0.991 \\
\hline Persistent, n (\%) & $5(5.9)$ & $3(3.5)$ & 0.459 \\
\hline Long-standing, n (\%) & $11(12.9)$ & $9(10.5)$ & 0.614 \\
\hline Permanent, n (\%) & $4(4.7)$ & $2(2.3)$ & 0.398 \\
\hline CAD, n (\%) & $10(11.8)$ & $4(4.7)$ & 0.090 \\
\hline Arterial hypertension, n (\%) & $46(54.1)$ & $42(48.8)$ & 0.490 \\
\hline Diabetes mellitus, n (\%) & $4(4.7)$ & $5(5.8)$ & 0.746 \\
\hline $\begin{array}{l}\text { Moderate renal impairment, } \mathrm{n} \\
(\%)\end{array}$ & $1(1.2)$ & $1(1.2)$ & 0.993 \\
\hline Peripheral vascular disease, n (\%) & $5(5.9)$ & $3(3.5)$ & 0.459 \\
\hline Cerebrovascular disease, n (\%) & $5(5.9)$ & $4(4.7)$ & 0.719 \\
\hline LV EF, \% & $65.5(49-80)$ & $67.0(51-89)$ & 0.212 \\
\hline PA pressure, mm Hg & $48.5(29-80)$ & $45.0(29-94)$ & 0.053 \\
\hline
\end{tabular}

$S R$ semirigid ring, $F B$ flexible band, $B M I$ body mass index, $B S A$ body surface area, NYHA New York Heart Association functional class, $A F$ atrial fibrillation, $C A D$ coronary artery disease, $L V E F$ left ventricle ejection fraction, $P A$ pulmonary artery

cardioplegic solution (Custodiol ${ }^{\odot}$ HTK Solution, Dr. Franz Köhler Chemie, Alsbach-Hahnlein, Germany) was used for myocardial protection with antegrade root flow.

The two most experienced surgeons in MV repair in our Institute performed the operations in the study. Surgeons were evenly split between the treatment groups. The surgical technique for MV repair was chosen according to the MV lesion (Table 2). The most common techniques were quadrangular ("sliding maneuver") or triangular resection for posterior MV prolapse, and artificial chordal replacement (separate or loop technique) for anterior leaflet pathology. The minimally invasive approach through the right fourth intercostal space with femoral-femoral cannulation for arterial and venous lines was used in $29.4 \%(n=25)$ and $31.4 \%(n=27)$ of patients in the SR and FB groups, respectively.

All mitral valve repairs were performed with flexible bands ("C Flex", CardiaMed, Penza, Russia) or complete rings ("D Ring", CardiaMed, Penza, Russia), which routinely use since 2005 . The ring size was selected according to the size of the anterior leaflet and the intertrigonal distance. In Barlow's cases, 36-40 mm rings were used. Flexible bands were implanted along the posterior mitral semicircle with an extension to both commissures for 3-5 mm. Valve competence was assessed intraoperatively by saline test and "ink-test" (symmetrical closure line, coaptation depth $\geq 5 \mathrm{~mm}$, absence of leaflet prolapse and regurgitation jet).

After bypass weaning, patients were followed-up with TEE. In cases with residual $\mathrm{MR} \geq$ grade 2 , cardiopulmonary bypass was re-established, and the valve was rerepaired or replaced; residual MR grade 1 (mild) was left alone. Intraoperative data and concomitant procedures are shown in Table 2.

\section{Patient follow-up}

All patients underwent TTE evaluation before discharge. In total, 170 patients were discharged and followed-up periodically by cardiologists and surgeons. After discharge, examinations were scheduled annually. When annual clinic visits were unavailable, follow-up was performed by contact with the referring cardiologist, the patient or their family. Anticoagulation therapy with an international normalized ratio (INR) target in the range of 2.5-3.0 was prescribed for all patients after surgery. The decision to stop anticoagulation therapy with Coumadin was based on echocardiography (normal left ventricle function, presence of atrial contractility) and Holter data (absence of atrial fibrillation, flutter, tachycardia) after 3 months. Echocardiograms obtained from outside physicians were re-analyzed at our Institute by the most experienced echocardiographers. Clinical follow-up was completed in 165 patients (97.1\%), and five patients were lost to follow-up. Follow-up echocardiography was performed 6-12 months after the operation and every year thereafter. Seventy-nine (94.0\%) of the 84 discharged patients in the SR group and $78(90.7 \%)$ of the 86 patients in the FB group underwent follow-up TTE. The mean duration from the operation to echocardiographic follow-up was 20.2 (95\% confidence interval [CI], 18.6-21.8) months. The mean clinical follow-up period was 24.7 (95\% CI, 23.5-27.0) months.

\section{Statistical analysis}

Assuming 5\% significance (two sided), 80\% power, event rates of 20 and $5 \%$ in the complete ring and flexible band groups, respectively, and a hazard ratio for 
Table 2 Intraoperative data

\begin{tabular}{|c|c|c|c|}
\hline & $\begin{array}{l}\text { SR Group, } \\
n=85\end{array}$ & $\begin{array}{l}\text { FB Group, } \\
n=86\end{array}$ & $P$ value \\
\hline \multicolumn{4}{|l|}{ Approach: } \\
\hline Conventional, n (\%) & $60(70.6)$ & $59(65.1)$ & 0.778 \\
\hline Minimally invasive, n (\%) & $25(29.4)$ & $27(31.4)$ & 0.778 \\
\hline CPB time, min & $140(110 ; 179.5)$ & $160(122 ; 206)$ & 0.091 \\
\hline \multicolumn{4}{|l|}{ Cross clamp time, min: } \\
\hline Conventional & $92(73 ; 117)$ & $101(79 ; 125)$ & 0.230 \\
\hline Minimally invasive & $116(101 ; 129)$ & $123(106 ; 156)$ & 0.171 \\
\hline \multicolumn{4}{|c|}{ Mitral valve analyze and intervention in certain patients } \\
\hline$A_{1}$ prolapse, $n(\%)$ & $9(10.6)$ & $11(12.8)$ & 0.654 \\
\hline $\mathrm{A}_{2}$ prolapse, $\mathrm{n}(\%)$ & $23(27.1)$ & $33(38.4)$ & 0.115 \\
\hline $\mathrm{A}_{3}$ prolapse, $\mathrm{n}(\%)$ & $13(15.3)$ & $19(22.1)$ & 0.254 \\
\hline $\mathrm{P}_{1}$ prolapse, $\mathrm{n}(\%)$ & $6(7.1)$ & $12(13.9)$ & 0.142 \\
\hline $\mathrm{P}_{2}$ prolapse, $\mathrm{n}(\%)$ & $59(69.4)$ & $68(79.1)$ & 0.119 \\
\hline $\mathrm{P}_{3}$ prolapse, $\mathrm{n}(\%)$ & $17(20.0)$ & $27(31.4)$ & 0.088 \\
\hline AMVL prolapse, n (\%) & $31(36.5)$ & $40(46.5)$ & 0.183 \\
\hline PMVL prolapse, n (\%) & $73(85.9)$ & $74(86.1)$ & 0.975 \\
\hline DMVL prolapse, n (\%) & $19(22.4)$ & $28(32.5)$ & 0.135 \\
\hline Chordae rupture, n (\%) & $64(75.3)$ & $53(61.6)$ & 0.055 \\
\hline AMVL resection, n (\%) & $1(1.2)$ & $4(4.7)$ & 0.178 \\
\hline PMVL resection, n (\%) & $37(43.5)$ & $49(56.9)$ & 0.079 \\
\hline AMVL neochordae, n (\%) & $22(25.9)$ & $29(33.7)$ & 0.263 \\
\hline PMVL neochordae, n (\%) & $30(35.3)$ & $27(31.4)$ & 0.589 \\
\hline Ring size, mm & $32(30 ; 32)$ & $34(30 ; 34)$ & 0.456 \\
\hline \multicolumn{4}{|l|}{ Concomitant procedure } \\
\hline Maze IV procedure, n (\%) & $18(21.2)$ & $14(16.3)$ & 0.412 \\
\hline CABG, n (\%) & $10(11.8)$ & $4(4.7)$ & 0.090 \\
\hline TV repair, n (\%) & $32(37.6)$ & $24(27.9)$ & 0.175 \\
\hline SAM-syndrome, n (\%) & 0 & $1(1.2)$ & 0.319 \\
\hline \multicolumn{4}{|l|}{ Intraoperative TEE } \\
\hline Depth of coaptation, mm & $9(7 ; 11)$ & $6(5 ; 8)$ & 0.006 \\
\hline Peak MV gradient, mm Hg & $8.0(6.7 ; 10.9)$ & $6.4(4 ; 9)$ & $<0.001$ \\
\hline Mean MV gradient, mm Hg & $3(2.4 ; 4)$ & $2(2 ; 3.9)$ & $<0.001$ \\
\hline
\end{tabular}

$S R$ semirigid ring, $F B$ flexile band, $A M V L$ anterior mitral valve leaflet, $P M V L$ posterior mitral valve leaflet, DMVL prolapse dual (anterior and posterior) mitral valve leaflet prolapse, $C A B G$ coronary artery bypass grafting, $T V$ tricuspid valve, $C P B$ cardiopulmonary bypass, TEE transesophageal echocardiography

significant MR recurrence of 0.23 and expected 5\% withdrawal rate, the sample size (total $n=170$ in both groups) was calculated using log-rank test (Freedman method) of freedom from MR recurrences in two groups. Data are presented as mean \pm SD or median with range. The variables of the two groups were compared using the unpaired $t$ test for continuous variables with normal distribution or the Mann-Whitney $U$ test for other distributions. To analyze the risk factors of early postoperative complications, we reviewed preoperative and intraoperative variables (Tables 1, 2, 3); a multivariate logistic regression model was used to calculate odds ratios (ORs). Estimates of survival and event-free survival for reoperation and the recurrence of significant MR were calculated using the Kaplan-Meier method and are reported with 95\% CIs. Patients were censored at the time of reoperation or at the time of death. Estimates are reported with their standard errors. Comparison of the curves was established by using the log-rank test for mid-term results. To analyze risk factors of late mortality, reoperation, and MR recurrence, we reviewed preoperative and intraoperative variables (Tables 1,2, 3); multivariable Cox proportional hazard regression models were used to calculate HRs. HRs and 95\% CIs were calculated. The inclusion criterion for the multivariable model was $P$ value $\leq 0.2$ ) in the univariable analysis. The significance level in the final "multivariable" model assessed as the 0.05. Stata/MP for Windows v. 13.0 (StataCorp. 2013. Stata Statistical Software: Release 13. College Station, TX: StataCorp LP.) was used for the statistical analysis.

\section{Availability of data and materials}

The data that support the findings of this study are available from Meshalkin National Medical Research Center but restrictions apply to the availability of these data, which were used under license for the current study, and so are not publically available. Data are however available from the authors upon reasonable request and with permission of Meshalkin National Medical Research Center.

\section{Results}

Overall repair rate was $95 \%$. The mean (median) cross clamp time did not differ between the SR and FB groups. The subgroup analysis of variances by the surgical approach revealed no differences in cross clamp time between the minimally invasive (25 and 27 patients, respectively, $p=0.171)$ and median sternotomy subgroups (60 and 59 patients, respectively, $p=0.230$ ).

The incidence of systolic anterior motion (SAM) syndrome was observed in 1 patient in the FB group. Conservative management was not effective and SAM was successfully treated using posterior MV leaflet folding technique. Two patients from SR group were rerepaired due to residual moderate MR revealed by intraoperative TEE.

Intraoperative TEE control revealed that MV coaptation depth was significantly higher in the SR group than the FB group (9 [7-11] vs. 6 [5-8] $\mathrm{mm} ; p=0.006$ ); however, the FB group had a lower rate of peak and mean transmitral pressure gradients $(p<0.001$; Table 2$)$.

There were no early (at 30/60/90 days) deaths. One 65 years old man with p3 prolapse and coronary artery 
Table 3 Echocardiography data

\begin{tabular}{|c|c|c|c|c|c|c|c|c|c|c|c|c|c|}
\hline & \multicolumn{5}{|c|}{ SR Group, $n=85$} & \multicolumn{5}{|c|}{ FB Group, $n=86$} & \multicolumn{3}{|c|}{ Group comparison, $P$ value } \\
\hline & Baseline & $\begin{array}{l}\text { At } \\
\text { discharge }\end{array}$ & $\begin{array}{l}P \text { value at } \\
\text { discharge }\end{array}$ & $\begin{array}{l}\text { Follow } \\
\text { up, } n=79\end{array}$ & $\begin{array}{l}P \\
\text { value }\end{array}$ & Baseline & $\begin{array}{l}\text { At } \\
\text { discharge }\end{array}$ & $\begin{array}{l}P \text { value at } \\
\text { discharge }\end{array}$ & $\begin{array}{l}\text { Follow up, } \\
n=78\end{array}$ & $\begin{array}{l}P \\
\text { value }\end{array}$ & Baseline & $\begin{array}{l}\text { At } \\
\text { discharge }\end{array}$ & $\begin{array}{l}\text { Follow } \\
\text { up }\end{array}$ \\
\hline $\mathrm{RA}, \mathrm{cm}$ & $\begin{array}{l}5.4(4.1- \\
8.9)\end{array}$ & $\begin{array}{l}4.9(4.0- \\
7.9)\end{array}$ & $<0.001$ & $\begin{array}{l}4.8(3.6- \\
7.8)\end{array}$ & 0.499 & $\begin{array}{l}5.3(3.3- \\
8.5)\end{array}$ & $\begin{array}{l}4.8(3.7- \\
6.8)\end{array}$ & $<0.001$ & $\begin{array}{l}4.8(3.0- \\
7.5)\end{array}$ & 0.805 & 0.155 & 0.187 & 0.204 \\
\hline $\mathrm{LA}, \mathrm{cm}$ & $\begin{array}{l}6.1(4.3- \\
9.6)\end{array}$ & $\begin{array}{l}5.2(4.4- \\
8.2)\end{array}$ & $<0.001$ & $\begin{array}{l}5.1(3.5- \\
7.9)\end{array}$ & 0.460 & $\begin{array}{l}5.7(4.4- \\
9.5)\end{array}$ & $\begin{array}{l}5.1(4.0- \\
7.2)\end{array}$ & $<0.001$ & $\begin{array}{l}4.9(3.2- \\
7.2)\end{array}$ & 0.070 & 0.070 & 0.067 & 0.291 \\
\hline $\begin{array}{l}\text { S MO (Doppler) } \\
\mathrm{cm}^{2}\end{array}$ & $\begin{array}{l}3.8(2.6- \\
6.9)\end{array}$ & $\begin{array}{l}3.3 \\
(2.4 ; 7.6)\end{array}$ & $<0.001$ & $\begin{array}{l}3.2(1.9- \\
5.7)\end{array}$ & 0.806 & $\begin{array}{l}4.1(2.8- \\
9.8)\end{array}$ & $\begin{array}{l}3.3(2.6- \\
4.9)\end{array}$ & $<0.001$ & $\begin{array}{l}3.3(1.8- \\
4.8)\end{array}$ & 0.054 & 0.062 & 0.202 & 0.699 \\
\hline $\begin{array}{l}\text { Peak MV pressure } \\
\text { gradient, } \mathrm{mm} \mathrm{Hg}\end{array}$ & $\begin{array}{l}8.7(3- \\
24)\end{array}$ & $\begin{array}{l}8.8(2.7- \\
17.0)\end{array}$ & 0.684 & $\begin{array}{l}8.5(3.9- \\
17)\end{array}$ & 0.206 & $\begin{array}{l}7.9(3.0- \\
22.0)\end{array}$ & $\begin{array}{l}7.0(2.1- \\
15.2)\end{array}$ & 0.027 & $6(2.1-18.0)$ & 0.212 & 0.680 & $<0.001$ & $<0.001$ \\
\hline $\begin{array}{l}\text { Mean MV pressure } \\
\text { gradient, } \mathrm{mm} \mathrm{Hg}\end{array}$ & $2.8(1-8)$ & $\begin{array}{l}3.0(1.0- \\
8.0)\end{array}$ & 0.236 & $\begin{array}{l}3.7(1.3- \\
8.0)\end{array}$ & 0.288 & $\begin{array}{l}2.6(1.0- \\
7.0)\end{array}$ & $\begin{array}{l}2.7(0.9- \\
5.7)\end{array}$ & 0.872 & $\begin{array}{l}2.8(0.6- \\
6.8)\end{array}$ & 0.232 & 0.985 & 0.002 & 0.001 \\
\hline Severe MR, n (\%) & $85(100)$ & 0 & $<0.001$ & $7(8.9)$ & 0.023 & $86(100)$ & 0 & $<0.001$ & $1(1.3)$ & 1.0 & 1.0 & 1.0 & 0.031 \\
\hline $\begin{array}{l}\text { Total moderate or } \\
\text { severe MR, } \mathrm{n}(\%)\end{array}$ & $85(100)$ & $5(5.9)$ & $<0.001$ & $12(15.2)$ & 0.023 & $86(100)$ & $4(4.6)$ & $<0.001$ & $7(9.0)$ & 0.248 & 1.0 & 0.719 & 0.343 \\
\hline LV EDD, cm & $\begin{array}{l}5.78 \pm \\
0.59\end{array}$ & $\begin{array}{l}5.03 \pm \\
0.53\end{array}$ & $<0.001$ & $\begin{array}{l}4.82 \pm \\
0.67\end{array}$ & 0.135 & $\begin{array}{l}5.78 \pm \\
0.74\end{array}$ & $\begin{array}{l}5.04 \pm \\
0.52\end{array}$ & $<0.001$ & $4.83 \pm 0.47$ & 0.017 & 0.962 & 0.874 & 0.908 \\
\hline LV ESD, cm & $\begin{array}{l}3.49 \pm \\
0.55\end{array}$ & $\begin{array}{l}3.36 \pm \\
0.49\end{array}$ & 0.055 & $3.3 \pm 0.7$ & 0.731 & $\begin{array}{l}3.51 \pm \\
0.71\end{array}$ & $\begin{array}{l}3.35 \pm \\
0.58\end{array}$ & 0.783 & $3.15 \pm 0.46$ & $<0.001$ & 0.815 & 0.891 & 0.263 \\
\hline LV EDV, ml & $\begin{array}{l}172.5 \pm \\
42.0\end{array}$ & $\begin{array}{l}120.9 \pm \\
32.6\end{array}$ & $<0.001$ & $\begin{array}{l}111.2 \pm \\
42.7\end{array}$ & 0.487 & $\begin{array}{l}169.0 \pm \\
50.0\end{array}$ & $\begin{array}{l}123.4 \pm \\
32.3\end{array}$ & $<0.001$ & $105 \pm 23.1$ & 0.001 & 0.624 & 0.618 & 0.375 \\
\hline LV ESV, ml & $\begin{array}{l}53.0 \\
(19-145)\end{array}$ & $\begin{array}{l}44.5(22- \\
135)\end{array}$ & $<0.001$ & $\begin{array}{l}35(18- \\
102)\end{array}$ & 0.130 & $\begin{array}{l}50.5 \\
(16-146)\end{array}$ & $\begin{array}{l}45(20- \\
140)\end{array}$ & 0.165 & $\begin{array}{l}38(18- \\
154)\end{array}$ & $<0.001$ & 0.127 & 0.360 & 0.808 \\
\hline LV EF, \% & $\begin{array}{l}65.5 \\
(49-80)\end{array}$ & $\begin{array}{l}61(35- \\
76)\end{array}$ & $<0.001$ & $\begin{array}{l}61(35- \\
87)\end{array}$ & 0.518 & $\begin{array}{l}67.0 \\
(51-89)\end{array}$ & $\begin{array}{l}59(35- \\
78)\end{array}$ & $<0.001$ & 65 (36-78) & $<0.001$ & 0.212 & 0.247 & 0.043 \\
\hline $\begin{array}{l}\text { PA systolic pressure, } \\
\mathrm{mm} \mathrm{Hg}\end{array}$ & $\begin{array}{l}48.5 \\
(42 ; 56)\end{array}$ & $\begin{array}{l}36(29- \\
46)\end{array}$ & 0.003 & $\begin{array}{l}34.5(20- \\
68)\end{array}$ & 0.080 & $\begin{array}{l}45 \\
(39 ; 54.5)\end{array}$ & $\begin{array}{l}36.5(25- \\
49)\end{array}$ & $<0.001$ & $29.5(8-48)$ & 0.833 & $0.0 \mathrm{n} 3$ & 0.416 & $<0.001$ \\
\hline
\end{tabular}

$S R$ semirigid ring, $F B$ flexible band, $R A$ size of right atrium, $L A$ size of left atrium, $S M O$ mitral orifice area, $M V$ mitral valve, $M R$ mitral regurgitation, $L V$ left ventricle, EDD end diastolic diameter, ESD end systolic diameter, EDV end diastolic volume, ESV end systolic volume, EF ejection fraction, $P A$ pulmonary artery

disease who was underwent triangular posterior leaflet resection and concomitant CABG in the SR group died after 6 months of hospital stay because of severe multiple organ failure. Two patients (one from each group) with severe LV systolic dysfunction in early postoperative period required extracorporeal life support with complete recovering after 7 days.

The mean intensive care unit stay was 2 days in both groups $(p=0.453)$. Ventilation and inotropic support time also did not differ between the groups (Table 4). There were no significant differences in terms of heart failure, prolonged ventilation or requirement of extracorporeal life support. Electrical cardioversion for atrial fibrillation paroxysm was required in $7(8.2 \%)$ and $3(3.5 \%)$ cases in the SR and FB groups, respectively $(p=0.186)$. Five patients (SR group, 4 vs. FB group, $1 ; p=0.169$ ) were reexplored for bleeding on the first postoperative day. Pacemaker implantation rates were $5.9 \%$ (due to sinus node dysfunction, 3 patients; complete AVconductance disturbances, 2 patients) and 4.7\% (due to sinus node dysfunction, 3 patients; complete AVconductance disturbances, 1 patient) in the SR and FB groups, respectively $(p=0.719)$.
There were no significant between-group differences in major valve-related complications. There were no cases of thromboembolic events, leakage, or structural dysfunction. There were 4 cases of transient ischemic attack with reversible neurologic deficits in the SR group versus none in the $\mathrm{FB}$ group $(p=0.042)$.

The median length of hospital stay after MV repair in the SR and FB groups was 17 (9-178) and 17 (7-36) days, respectively $(p=0.455$, Table 4$)$. The preoperative independent predictor of heart failure was left ventricular ejection fraction (LVEF) (OR, 0.94; 95\% CI, 0.9-0.98); of myocardial infarction - cardiopulmonary bypass time with 1-min step (OR, 1.03; 95\% CI, 1.01-1.1); and prolonged ventilation - preoperative NYHA functional class (OR, 2.6; 95\% CI, 1.2-5.7).

\section{Echocardiographic results}

All echocardiographic parameters significantly changed from the preoperative to immediate postoperative period at discharge, except transmitral pressure gradients and LV end-systolic diameter (LVESD) (Table 3). There were no significant between-group differences in changes in LV function and left and right atria remodeling; however, transmitral peak and mean pressure gradients were 
significantly lower in the FB group. The mitral orifice area did not differ between the groups. The TTE before discharge revealed that $5(5.9 \%)$ and $4(4.7 \%)$ patients in the SR and FB groups, respectively, had grade 2 residual MR $(p=0.719)$. Follow-up echocardiography data at 24 months are shown in Table 3. The repeated-measures analysis of variance in the FB group revealed significant changes in LV end-diastolic diameter (LVEDD), LV enddiastolic volume (LVEDV), and LV end-systolic volume (LVESV) at discharge; moreover, these parameters and LVESD were also decreased at 24 months of follow up. Meanwhile, the LVEF significantly decreased at discharge; however, it significantly increased during the follow-up. In the SR group, there were no significant

Table 4 Early (30-days) results

\begin{tabular}{|c|c|c|c|}
\hline & $\begin{array}{l}\text { SR Group, } \\
n=85\end{array}$ & $\begin{array}{l}\text { FB Group, } \\
n=86\end{array}$ & $P$ value \\
\hline Hospital mortality ${ }^{\mathrm{a}}, \mathrm{n}(\%)$ & $1(1.2)$ & 0 & 0.313 \\
\hline ICU stay, days & $2(1-14)$ & $2(1-14)$ & 0.453 \\
\hline Ventilation time, h & $7(0-49)$ & $5(1-41)$ & 0.068 \\
\hline Inotropic support, h & $10(0-151)$ & $14(0-105)$ & 0.591 \\
\hline Heart failure, n (\%) & $23(27.1)$ & $19(22.1)$ & 0.451 \\
\hline Prolonged ventilation, n (\%) & $14(16.5)$ & $15(17.4)$ & 0.866 \\
\hline ECLS, n (\%) & $1(1.2)$ & $1(1.2)$ & 0.993 \\
\hline AF Early paroxysm, n (\%), & $39(45.9)$ & $30(34.9)$ & 0.143 \\
\hline Electrical cardioversion, n (\%) & $7(8.2)$ & $3(3.5)$ & 0.186 \\
\hline \multicolumn{4}{|l|}{ Valve-related complications, n (\%): } \\
\hline MI, n (\%) & $5(5.9)$ & $3(3.5)$ & 0.459 \\
\hline TIA, n (\%) & $4(4.7)$ & 0 & 0.042 \\
\hline Stroke, n (\%) & 0 & $1(1.2)$ & 0.319 \\
\hline$A K F, n(\%)$ & $5(5.9)$ & $4(4.7)$ & 0.719 \\
\hline $\mathrm{IE}, \mathrm{n}(\%)$ & $1(1.2)$ & $1(1.2)$ & 0.993 \\
\hline Ring dehiscence, n (\%) & $1(1.2)$ & 0 & 0.313 \\
\hline Leak, n (\%) & 0 & 0 & - \\
\hline Thrombosis, n (\%) & 0 & 0 & - \\
\hline Other embolic events, n (\%) & 0 & 0 & - \\
\hline Structural dysfunction, n (\%) & 0 & 0 & - \\
\hline Bleeding, n (\%); & $9(10.6)$ & $6(7.0)$ & 0.404 \\
\hline Re-exploration for bleeding, n (\%) & $4(4.7)$ & $1(1.2)$ & 0.169 \\
\hline Lymphorrhea, n (\%) & 0 & $1(1.2)$ & 0.319 \\
\hline Pacemaker implantation, n (\%) & $5(5.9)$ & $4(4.7)$ & 0.719 \\
\hline Pleural effusion, n (\%) & $14(16.5)$ & $20(23.2)$ & 0.266 \\
\hline Deep sternal infection, n (\%) & 0 & 0 & - \\
\hline Superficial infection, n (\%) & $1(1.2)$ & $1(1.2)$ & 0.993 \\
\hline Hospital stay, days & $17(9-178)$ & $17(7-36)$ & 0.455 \\
\hline
\end{tabular}

$S R$ semirigid ring, $F B$ flexible band, $I C U$ intensive care unit, $E C L S$ extracorporeal life support, $A F$ atrial fibrillation, $M I$ myocardial infarction, $T I A$ transient ischemic attack, AKF acute kidney failure, IE infective endocarditis ahospital death occurred 6 months after surgery differences in LV function changes at serial examinations. We also revealed higher transmitral pressure gradients in the SR group, including significant differences in systolic pulmonary artery pressure among patients with sinus rhythm, with favorable results in the FB group.

\section{Survival analysis}

At the latest follow-up, 158 patients were alive. There were 3 late deaths among the 84 patients in the SR group (mortality $3.6 \%$ ), and 4 late deaths among the 81 patients in the FB group (mortality $4.9 \%$ ). The causes of death in the SR group were endocarditis (1 case), malignancy (1 case), and unknown cause (1 case); two of them were regarded as cardiac-related deaths. The causes of death in the FB group were ischemic stroke (2 cases), acute myocardial infarction (1 case), and pulmonary edema (1 case), all of which were cardiac-related. The Kaplan-Meier survival rates at 2 years were 96.0 $\pm 2.3 \%$ (95\% CI, $88.6-98.7 \%)$ and $94.3 \pm 2.8 \%$ (95\% CI, 85.5-97.9\%) in the SR and FB groups, respectively (Figure 2) (log-rank, $p=0.899$ ).

The Kaplan-Meier freedom from cardiac-related death at 2 years was $97.7 \pm 2.0 \%(95 \% \mathrm{CI}, 89.1-99.3 \%)$ and $94.3 \pm 2.8 \%(95 \% \mathrm{CI}, 85.5-97.9 \%)$ in the $\mathrm{SR}$ and $\mathrm{FB}$ groups, respectively (Additional file 1: Figure S1) (logrank, $p=0.411)$. The multivariable Cox regression hazard model did not identify independent risk factors of late death.

\section{Clinical status}

Before surgery, $65.9 \%$ and $52.3 \%$ of patients in the SR and FB groups, respectively, had an NYHA functional classification of III and IV. Most patients demonstrated significant improvement of functional capacity at the last follow-up $(43.2 \%$ and $34.6 \%$ of 81 SR patients and $44.1 \%$ and $40.3 \%$ of 77 FB patients had an NYHA functional classification of I and II, respectively). A total of $57(75 \%)$ and $61(84.7 \%)$ patients presented with sinus rhythm in the $\mathrm{SR}$ and $\mathrm{FB}$ groups, respectively $(p=0.201)$.

\section{Thromboembolism and anticoagulation-related hemorrhage}

There was no major bleeding case during follow-up. Two patients form each group had transient ischemic attack. In the FB group, 2 out of 3 patients who had stroke died. Two patients had atrial fibrillation and were kept on anticoagulation therapy, and another one was in sinus rhythm at the last follow up and was not anticoagulated. Central retina occlusion occurred in 1 case in each group. The overall freedom from thromboembolic events at 3 years after $\mathrm{MV}$ repair in the SR and $\mathrm{FB}$ groups was $94.7 \pm 3.6 \%(95 \% \mathrm{CI}, 80.6-98.7 \%)$ and 
$90.8 \pm 3.7 \%$ (95\% CI, 80.4-95.9\%), respectively (logrank, $p=0.416)$.

\section{Infective endocarditis}

Three patients had infective endocarditis. Two of them were in the SR group, and one of them died because of pacemaker lead endocarditis and heart failure. The 2 patients who survived were treated with antibiotics alone. Freedom from infective endocarditis at 3 years was $97.3 \pm 1.9 \%(95 \% \mathrm{CI}, 89.4-99.3 \%)$ and $98.5 \pm 1.5 \%$ (95\% CI, 89.9-99.8\%) in the SR and FB groups, respectively (log-rank, $p=0.573$ ).

\section{Recurrence of mitral regurgitation}

Moderate or severe MR was observed in 12 (15.2\%) of 79 patients and 7 (9.0\%) of 78 patients in the SR and FB groups, respectively $(p=0.343)$. Among them, 3 patients in the SR group underwent redo MV surgery. The Kaplan-Meier estimate for freedom from recurrence of moderate or severe MR at 2 years was $85.3 \pm 5.0 \% \quad(95 \%$ CI, $71.9-92.6 \%)$ and $95.3 \pm 2.7 \%$ (95\% CI, 85.9-98.5\%) in the SR and FB groups, respectively, (log-rank test, $p=0.011$ ) (Figure $3 \mathrm{~A})$. The multivariable Cox proportional hazard model identified residual MR before discharge as an independent risk factor of late recurrence of significant MR (HR, 4.1; 95\% CI, 1.5-11.5) (Additional file 2: Table S1).

Among them, severe MR was observed in 7 (9.7\%) and $1(1.3 \%)$ patient(s) in the SR and FB groups, respectively. The Kaplan-Meier estimate for freedom from severe MR at 2 years was $84.8 \pm 6.8 \%$ (95\% CI, 65.1-93.8\%) and $98.7 \pm 1.3 \%(95 \% \mathrm{CI}, 90.8-99.8 \%)$ in the SR and FB groups, respectively (log-rank test, $p=0.006$ ) (Figure 3B). The multivariable Cox proportional hazard model identified residual MR before discharge as an independent risk factor of late recurrence of severe MR (HR, 8.4; 95\% CI, 1.6-43.3).

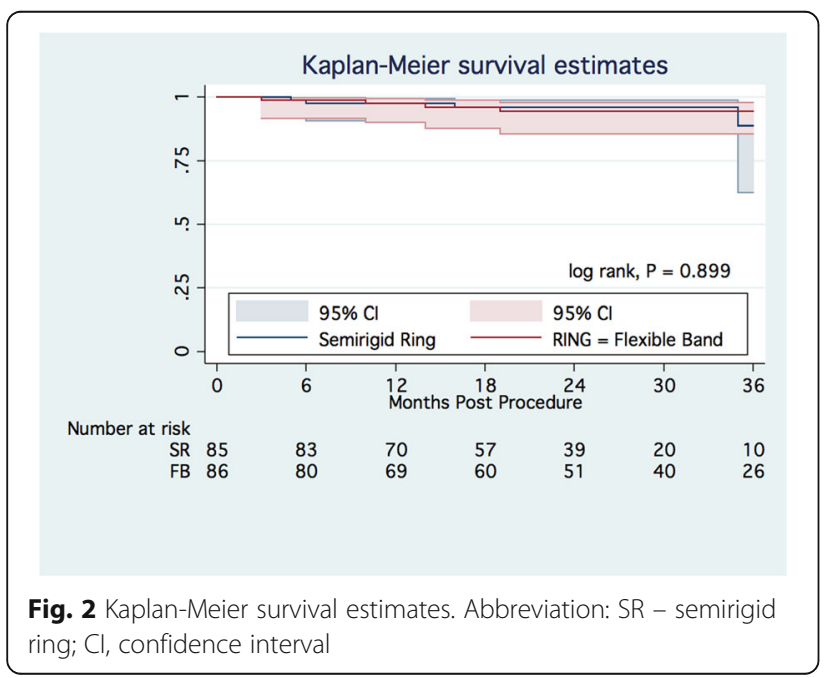

\section{Reoperations}

Reoperations were required in 3 patients in the SR group for partial ring dehiscence in all cases. The MV was rerepaired in 2 patients and replaced in 1 case. The KaplanMeier estimate for freedom from reoperation at 2 years of follow-up was $97.0 \pm 2.1 \%$ (95\% CI, 88.4-99.3\%) and 100\% in the SR and FB groups, respectively (Figure 4) (log-rank, $p=0.044)$. The Cox regression hazard model did not identify any preoperative or intraoperative risk factor of late reoperations.

\section{Discussion}

In the late 1960's, Carpentier developed annuloplasty rings, considered the "gold standard" for the surgical treatment of MR [11]. Subsequent studies showed that the MV annulus continually changes size and shape during the cardiac cycle [12-14]. This led to the development of a flexible ring that could conform to the physiologic changing annular shape $[15,16]$. However, there is controversy regarding the optimal mechanical characteristics of annuloplasty rings and the use of rigid rings or flexible bands in degenerative MV disease $[5,17]$.

David et al. [18] conducted one of the first randomized studies comparing the rigid ring (13 patients) and flexible ring (12 patients). The results showed significantly better LV systolic function and stroke volume/LVEDV index in the flexible group and no significant reduction in LVESV and LVESD in the rigid ring group. However, the clinical outcomes of these 2 ring types have not been reported. In the present study, there were similar results in LV changes with no significant differences between the SR and FB groups intermediately and 2 years postsurgery. However, only the FB group showed a significant reduction in LVEDD, LVESD, LVEDV, and LVESV (when comparing postoperative values and those 2 years postsurgery).

Chang et al. conducted the largest randomized trial (363 patients) comparing the Carpentier-Edwards rigid ring and flexible Duran annuloplasty ring [19]. The mean duration from the operation to follow-up echocardiography was $26.7 \pm 24.1$ months. LVEF, LVESD, and LVEDD parameters changed significantly at serial examinations in both groups with no significant difference between the two ring types. There were no significant differences in survival, reoperation rates, and recurrences of significant MR at a mean follow-up of $46.6 \pm 32.6$ months. However, their study was limited by the heterogeneous MR etiology, the long recruitment period, and the fact that the echocardiography parameters were not presented at separate time points, which may have caused bias.

Shahin et al. [20] conducted a randomized study comparing the Carpentier-Edwards rigid Classic and 

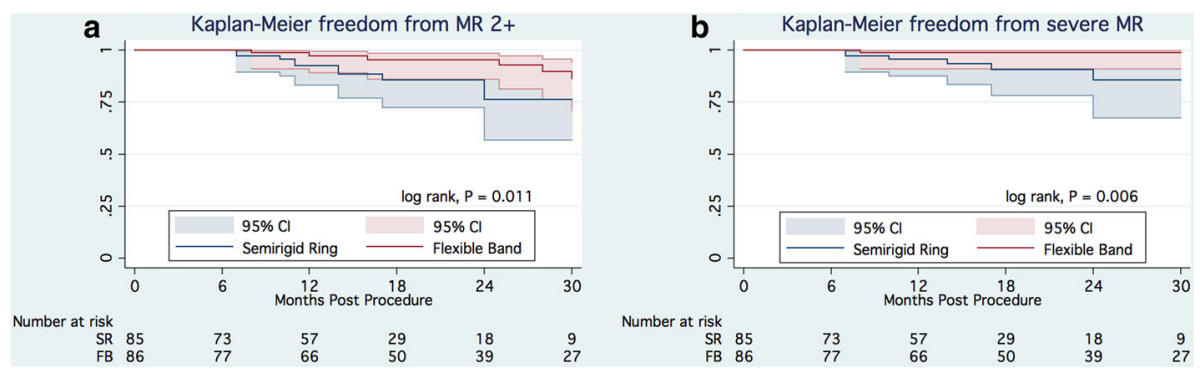

Fig. 3 a. Kaplan-Meier freedom from moderate and severe mitral regurgitation. b. Kaplan-Meier freedom from severe mitral regurgitation Abbreviation: MR, mitral regurgitation; SR - semirigid ring; Cl, confidence interval

semi-flexible Physio rings (mean follow up, 5.1 years). There were no between-groups differences in terms of mortality, morbidity, and LV function. However, an unexplained $16 \%$ difference in mortality was considered clinically important.

At least 3 randomized studies did not demonstrate the clinical benefits of flexible or rigid types of annuloplasty devices [18-20]. However, one of them [18] suggested better LV systolic function with flexible rings. Similar results were reported by Okada et al. [21], and concern that rigid rings could restrict LV wall motion was raised.

In a prospective echocardiographic study by UngerGraeber et al. [22], no significant difference was shown between the Carpentier rigid ring and flexible Duran ring in terms of transmitral velocity and pressure gradient. In contrast, our study showed higher transmitral pressure gradients in the SR group.

After David et al. criticized the rigid ring for impaired LV function [18] and Kreindel et al. [23] reported the potential risk of SAM syndrome after rigid ring annuloplasty, Carpentier et al. introduced a new concept of mitral annuloplasty with the semirigid prosthetic ring, which combines remodeling and flexibility [24]. At mid-term follow-up between 6 and 18 months, 93.2\% of 94 followed-up patients were free from MR

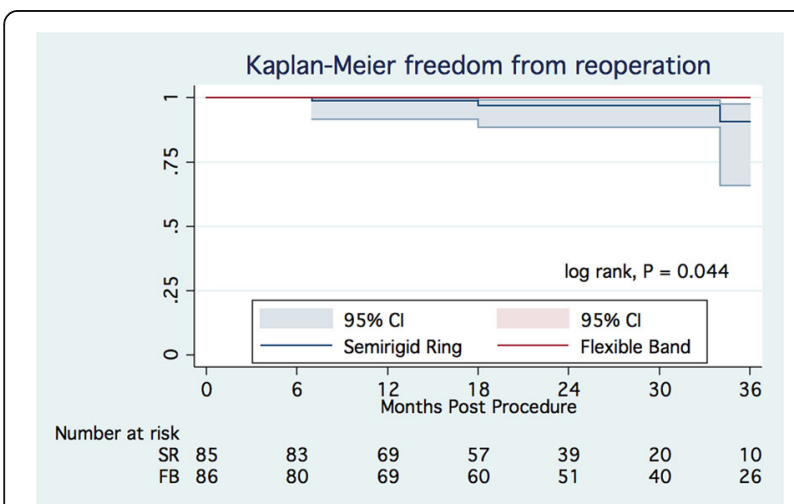

Fig. 4 Kaplan-Meier freedom from reoperations. Abbreviation: $\mathrm{SR}$ - semirigid ring; $\mathrm{Cl}$, confidence interval recurrence with a transmitral pressure gradient at $3.55 \pm 1.93 \mathrm{mmHg}$. Thereafter, excellent mid-term results with semirigid rings have been reported by other investigators $[25,26]$. Since then, the concept of a semirigid ring has gained popularity, and the semirigid ring (instead of the rigid ring) has been successfully adopted in mitral annuloplasty for degenerative MV disease. Flexible posterior annuloplasty bands have also shown high effectiveness in preserving mitral annulus flexibility and provide good mid-term and long-term durability $[4,27,28]$.

The semirigid ring and flexible ring have not been sufficiently compared. An animal randomized study [29] showed that LV function was not altered with either flexible or semirigid ring annuloplasty. A Japanese, retrospective, propensity score matched study [30] evaluated intermediate echocardiography results only. The overall cohort's LVEF decreased during the first week after surgery and then recovered gradually at 6 months and 1 year; LVEDD abruptly decreased and LVESD minimally decreased at the first week postoperatively, then gradually decreased at 6 months and later stabilized. There were no significant between-group differences in LVEF, LVEDD, and LVESD. They suggested that the semirigid ring might prevent LV impairment compared with the rigid ring. However, their study was limited by the retrospective design, low rate of followed-up patients, and difference in annuloplasty devices used in the flexible group.

Previously was shown that experience in mitral valve repair is an important determinant of operative efficiency and late survival [31], in our study both surgeons are well experienced and evenly split between groups. However, our results seem different to Castillo JG report [32]. We assume that limited experience in Barlow valves disease was influenced for our results. In this view complex mitral valve cases should be consolidated and addressed to one surgeon. It might be helpful to use scoring system [33] to allow stratification of complexity for degenerative mitral valve repair for improving results and develop local expertise. 
We examined the immediate and mid-term results of patients with degenerative MV disease who underwent primary MV repair with a complete semirigid ring or flexible posterior annuloplasty band. Both groups had comparable early clinical results; however, the SR group had better coaptation depth, while the FB group demonstrated significantly lower transmitral pressure gradients. At serial echocardiographic examinations, only the FB group showed significant LV remodeling. Consistent with previous studies, there were no between-group differences in overall survival, freedom from cardiacrelated death, and follow-up LV remodeling. Our study is the first to show the superiority of the flexible posterior band over the semirigid complete ring in terms of freedom from recurrences of significant and/or severe MR and risk of MV reoperation.

\section{Conclusion}

The present study is limited by the 2-year follow-up period and single-center design. Important limitation is low number of patients at late risk. Further study with a longer follow-up is warranted. In conclusion, patients with degenerative MV disease may benefit from valve repair with flexible bands. Residual MR is an independent risk factor of late insufficiency recurrence.

\section{Additional file}

Additional file 1: Figure S1. Kaplan-Meier freedom from cardiac-related death. Abbreviation: Cl, confidence interval. (TIFF 1293 kb)

Additional file 2: Table S1. Cox proportional hazard model for recurrence of significant MR. (DOCX $15 \mathrm{~kb}$ )

\section{Abbreviations \\ Cl: Confidence interval; HR: Hazard ratio; ITT: Intention-to-treat; LV: Left ventricle; LVEDD: Left ventricle end-diastolic diameter; LVEDV: Left ventricle end-diastolic volume; LVEF: Left ventricular ejection fraction; LVESD: Left ventricle end-systolic diameter; LVESV: Left ventricle end-systolic volume; MR: Mitral regurgitation; MV: Mitral valve; NYHA: New York Heart Association; OR: Odds ratio; SAM: Systolic anterior motion; TEE: Transesophageal echocardiography}

\section{Acknowledgements}

We would like to thank Editage for their editorial support.

\section{Funding}

This research received no specific grant from any funding agency in the public, commercial, or not-for-profit sectors.

\section{Availability of data and materials}

The data that support the findings of this study are available from Meshalkin National Medical Research Center but restrictions apply to the availability of these data, which were used under license for the current study, and so are not publically available. Data are however available from the authors upon reasonable request and with permission of Meshalkin National Medical Research Center.

\section{Authors' contributions}

Please contact author for data requests. All authors read and approved the final manuscript.
Ethics approval and consent to participate

Study was approved by local Ethical Committee at Aughust 1, 2011, approval number PA - 112

\section{Consent for publication}

Not applicable

\section{Competing interests}

The authors declare that they have no competing interests.

\section{Publisher's Note}

Springer Nature remains neutral with regard to jurisdictional claims in published maps and institutional affiliations.

Received: 10 September 2017 Accepted: 28 November 2017

Published online: 13 December 2017

\section{References}

1. Lillehei CW, Gott VL, Dewall RA, Varco RL. Surgical correction of pure mitral insufficiency by annuloplasty under direct vision. J Lancet. 1957;77:446-9.

2. Carpentier A. Cardiac valve surgery-the "French correction". J Thorac Cardiovasc Surg. 1983;86:323-37.

3. Filsoufi F, Carpentier A. Principles of reconstructive surgery in degenerative mitral valve disease. Semin Thorac Cardiovasc Surg. 2007;19:103-10.

4. Brown ML, Schaff HV, Li Z, Suri RM, Daly RC, Orszulak TA. Results of mitral valve annuloplasty with a standard-sized posterior band: is measuring important? J Thorac Cardiovasc Surg. 2009;138:886-91.

5. Hu X, Zhao Q. Systematic evaluation of the flexible and rigid annuloplasty ring after mitral valve repair for mitral regurgitation. Eur J Cardiothorac Surg. 2011:40:480-7.

6. Wan $\mathrm{S}$, Lee $\mathrm{AP}$, Jin $\mathrm{CN}$, Wong $\mathrm{RH}$, Chan $\mathrm{HH}, \mathrm{Ng} \mathrm{CS}$, et al. The choice of mitral annuloplastic ring-beyond "surgeon's preference". Ann Cardiothorac Surg. 2015:4:261-5.

7. Adams DH, Rosenhek $\mathrm{R}$, Falk $\mathrm{V}$. Degenerative mitral valve regurgitation: best practice revolution. Eur Heart J. 2010;31:1958-67.

8. Bonow RO, Carabello BA, Chatterjee K, de Leon AC Jr, Faxon DP, Freed MD, et al. 2008 Focused update incorporated into the ACC/AHA 2006 guidelines for the management of patients with valvular heart disease: a report of the American College of Cardiology/American Heart Association task force on practice guidelines (writing committee to revise the 1998 guidelines for the Management of Patients with Valvular Heart Disease): endorsed by the Society of Cardiovascular Anesthesiologists, Society for Cardiovascular Angiography and Interventions, and Society of Thoracic Surgeons. Circulation. 2008;118:e523-661.

9. Lancellotti P, Moura L, Pierard LA, Agricola E, Popescu BA, Tribouilloy C, et al. European Association of Echocardiography recommendations for the assessment of valvular regurgitation. Part 2. Mitral and tricuspid regurgitation (native disease). Eur J Echocardiogr. 2010;11:307-32.

10. Akins CW, Miller DC, Turina MI, Kouchoukos NT, Blackstone EH, Grukemeier $\mathrm{GL}$, et al. Guidelines for reporting mortality and morbidity after cardiac valve interventions. Ann Thorac Surg. 2008;85(4):1490-5.

11. Carpentier A. Reconstructive valvuloplasty. A new technique of mitral valvuloplasty. Presse Med. 1969;77:251-3.

12. Glasson JR, Komeda M, Daughters GT, Niczyporuk MA, Bolger AF, Ingels NB, et al. Three-dimensional regional dynamics of the normal mitral anulus during left ventricular ejection. J Thorac Cardiovasc Surg. 1996;111:574-85.

13. Grewal J, Suri R, Mankad S, Tanaka A, Mahoney DW, Schaff HV, et al. Mitral annular dynamics in myxomatous valve disease: new insights with real-time 3-dimensional echocardiography. Circulation. 2010;121:1423-31.

14. Lansac E, Lim KH, Shomura Y, Goetz WA, Lim HS, Rice NT, et al. Dynamic balance of the aortomitral junction. J Thorac Cardiovasc Surg. 2002;123:911-8.

15. Cosgrove DM, Arcidi JM, Rodriguez L, Stewart WJ, Powell K, Thomas JD. Initial experience with the Cosgrove-Edwards Annuloplasty system. Ann Thorac Surg. 1995;60:499-503. discussion 503-4

16. Dagum P, Timek T, Green GR, Daughters GT, Liang D, Ingels NB Jr, et al. Three-dimensional geometric comparison of partial and complete flexible mitral annuloplasty rings. J Thorac Cardiovasc Surg. 2001;122:665-73.

17. Chee T, Haston R, Togo A, Raja SG. Is a flexible mitral annuloplasty ring superior to a semi-rigid or rigid ring in terms of improvement in symptoms and survival? Interact Cardiovasc Thorac Surg. 2008;7:477-84. 
18. David TE, Komeda M, Pollick C, Burns RJ. Mitral valve annuloplasty: the effect of the type on left ventricular function. Ann Thorac Surg. 1989;47:524-7. discussion 527-8

19. Chang B, Youn Y, Ha J, Lim S, Hong Y, Chung N. Long-term clinical results of mitral valvuloplasty using flexible and rigid rings: a prospective and randomized study. J Thorac Cardiovasc Surg. 2007;133(4):995-1003.

20. Shahin GM, van der Heijden GJ, Bots ML, Cramer MJ, Jaarsma W, Gadellaa JC, et al. The Carpentier-Edwards classic and Physio mitral annuloplasty rings: a randomized trial. Heart Surg Forum. 2005;8:E389-94. discussion E394-5

21. Okada Y, Shomura T, Yamaura Y, Yoshikawa J. Comparison of the Carpentier and Duran prosthetic rings used in mitral reconstruction. Ann Thorac Surg. 1995;59:658-62. discussion 662-3

22. Unger-Graeber B, Lee RT, Sutton MS, Plappert M, Collins JJ, Cohn LH. Doppler echocardiographic comparison of the Carpentier and Duran anuloplasty rings versus no ring after mitral valve repair for mitral regurgitation. Am J Cardiol. 1991;67:517-9.

23. Kreindel MS, Schiavone WA, Lever HM, Cosgrove D. Systolic anterior motion of the mitral valve after Carpentier ring valvuloplasty for mitral valve prolapse. Am J Cardiol. 1986;57:408-12.

24. Carpentier AF, Lessana A, Relland JY, Belli E, Mihaileanu S, Berrebi AJ, et al. The "physio-ring": an advanced concept in mitral valve annuloplasty. Ann Thorac Surg. 1995;60:1177-85. discussion 1185-6

25. Raffoul R, Uva MS, Rescigno G, Belli E, Scorsin M, Pouillart F, et al. Clinica evaluation of the Physio annuloplasty ring. Chest. 1998:113:1296-301.

26. Accola KD, Scott ML, Thompson PA, Palmer GJ, Sand ME, Ebra G. Midterm outcomes using the physio ring in mitral valve reconstruction: experience in 492 patients. Ann Thorac Surg. 2005;79:1276-83. discussion 1276-83

27. Gillinov AM, Cosgrove DM 3rd, Shiota T, Qin J, Tsujino H, Stewart WJ, et al. Cosgrove-Edwards Annuloplasty system: midterm results. Ann Thorac Surg 2000;69:717-21.

28. Chitwood WR, Rodriguez E, Chu MW, Hassan A, Ferguson TB, Vos PW, et al. Robotic mitral valve repairs in 300 patients: a single-center experience. J Thorac Cardiovasc Surg. 2008;136:436-41.

29. Green GR, Dagum P, Glasson JR, Daughters GT, Bolger AF, Foppiano LE, et al. Semirigid or flexible mitral annuloplasty rings do not affect global or basal regional left ventricular systolic function. Circulation. 1998;98:I128-35 discussion II135-6

30. Manabe S, Kasegawa H, Fukui T, Tabata M, Shinozaki T, Shimokawa T, et al. Do semi-rigid prosthetic rings affect left ventricular function after mitral valve repair? Circ J. 2013;77:2038-42.

31. Burt BM, ElBardissi AW, Huckman RS, Cohn LH, Cevasco MW, Rawn JD, et al. Influence of experience and the surgical learning curve on long-term patient outcomes in cardiac surgery. J Thorac Cardiovasc Surg. 2015;150: 1061-68.e3.

32. Castillo JG, Anyanwu AC, Fuster V, Adams DH. A near 100\% repair rate for mitral valve prolapse is achievable in a reference center: implications for future guidelines. J Thorac Cardiovasc Surg. 2012;144:308-12.

33. Anyanwu AC, Itagaki S, Chikwe J, El-Eshmawi A, Adams DH. A complexity scoring system for degenerative mitral valve repair. J Thorac Cardiovasc Surg. 2016;151:1661-70.

\section{Submit your next manuscript to BioMed Central and we will help you at every step:}

- We accept pre-submission inquiries

- Our selector tool helps you to find the most relevant journal

- We provide round the clock customer support

- Convenient online submission

- Thorough peer review

- Inclusion in PubMed and all major indexing services

- Maximum visibility for your research

Submit your manuscript at www.biomedcentral.com/submit

CBiomed Central 